\title{
Difference in benthic invertebrate communities of headwater streams can be detected using a short elevation gradient
}

\author{
Armin Namayandeh $(\mathbb{D} \cdot$ David V. Beresford $\cdot$ Keith M. Somers • \\ Peter J. Dillon
}

Received: 4 January 2018/Accepted: 18 May 2018/Published online: 1 June 2018

(C) The Author(s) 2018

\begin{abstract}
Communities of benthic invertebrates from a series of intermittent headwater streams spanning over a short elevation gradient (i.e., 180-500 m) were investigated in April-July 2010 and May-July 2011. The main purpose of this study was to better understand whether the potential future effect of environmental change on biological communities of the Precambrian Shield's freshwaters can be detected using elevation as a substitute for time. Since obtaining long-term environmental data is a time-consuming process, substituting space for time could instead generate similar information in a shorter time. In this study, environmental differences associated with short elevation gradient were correlated with differences in benthic invertebrate communities. Therefore, elevation gradient provides a spatial proxy for anticipated future environmental change impacts over time. It was determined that water temperature accounts for the greatest variation in communities along the elevation. Many community metrics such as abundance, functional feeding groups, diversity, and evenness were significantly different based on the difference in elevation. Result indicates that even a short elevation gradient can potentially be used as a surrogate to look at the effect of environmental change.
\end{abstract}

Keywords Elevation · Benthic invertebrates · Communities · Headwater streams · Precambrian Shield

Electronic supplementary material The online version of this article (https://doi.org/10.1007/s40071-018-0197-2) contains supplementary material, which is available to authorized users.

\footnotetext{
A. Namayandeh $(\bowtie)$

Taxanama Corp., 25 Mabelle Ave., Toronto, ON, Canada

e-mail: a.namayan@taxanama.com

D. V. Beresford

Environmental and Life Sciences-Biology Department, Trent University, 2140 East Bank Drive, Peterborough,

ON K9L 1Z8, Canada

e-mail: davidberesford@trentu.ca

K. M. Somers

Department of Ecology and Evolutionary Biology, University of Toronto, Toronto, Canada

e-mail: keith.somers@ontario.ca

P. J. Dillon

Environmental and Life Sciences-Chemistry Department, Trent University, 1600 West Bank Drive, Peterborough, ON K9J 7B8, Canada

e-mail: pdillon@trentu.ca
} 


\section{Introduction}

Environmental factors such as water temperature, water velocity, food availability, and food type influence on the benthic invertebrate communities' structure along longitudinal stream profiles and with changes in altitude (Camargo and DeJalon 1995; Hawkins et al. 2000; Vannote et al. 1980). This is because a complex interaction exists between water temperature, flow regime, food quality, type and availability, and the substrate that determines environmental heterogeneity and contributes to species diversity (Minshall et al. 1985). This spatial heterogeneity has been investigated in terms of stream longitudinal profile from the headwater to the mouth within the context of the river continuum concept (e.g., Carter et al. 1996; Minshall et al. 1985; Scheibler et al. 2014; Scheibler and Debandi 2008; Vannote et al. 1980). However, few studies have compared streams at similar latitudes yet located at different elevations and inquired whether the spatial variation in altitude within the same geographic region can affect the community of benthos in streams (Jacobsen 2003, 2004, 2008; Jacobsen et al. 1997; Ramírez and Pringle 1998; Ramírez et al. 2008; Yule et al. 2009).

Jacobsen et al. (1997) have shown that when physical parameters such as size and current are accounted for, benthic assemblages from the tropical stream located at different altitude can be compared based on their thermal differences. In the same study, Jacobsen et al. (1997) have further illustrated that these streams are comparable with streams in different geographical regions (i.e., lowlands of Denmark). In addition, Jacobsen $(2003,2004)$ studies of Andean streams indicated that richness and diversity of benthic invertebrates of streams that are physico-chemically comparable changes along the altitudinal gradients. Therefore, altitude was not only useful to compare the benthic communities of several streams stretched along an elevation gradient, but was also a useful surrogate for detecting the effect of local environmental change on benthic communities. In areas with large elevation gradients, such as Andean regions, it would be easier to characterize and separate the streams spatially. This is because taxonomically different communities of benthic invertebrates are usually encountered. However, streams stretched over a short elevation gradient most probably have assemblage of similar invertebrates (i.e., taxonomically) that have differences only in abundance. The community difference based on the abundance can be detected if streams are in close geographical proximity, and therefore, species can migrate along the elevation gradient (Hughes et al. 2008).

Previous studies have proposed that freshwater systems of Ontario Precambrian Shield are vulnerable to effect of environmental change such as climatic change (Magnuson et al. 1997; Schindler et al. 1996). Obtaining long-term data on environmental variables is an expensive and time-consuming process. It should be possible to substitute space for time instead to generate similar information in a shorter period. The differences of environmental variables associated with an elevation gradient (e.g., temperature) corresponding to change in benthic invertebrate communities of comparable freshwaters can be potentially used for this purpose. In this study, we compared communities of benthic invertebrates from several hydrologically comparable intermittent headwater streams spanning an elevation gradient (i.e., 180-472 m) over a specific period (i.e., April-July 2010; May-July 2011) to determine whether their communities are different from one another based on community abundance and indices such as functional feeding groups (FFG), diversity, richness, and evenness. The objective was to determine whether the variance in biotic communities can be explained by local variable(s) that are associated with regional variable(s) as elevation changes. If variance is detected it would suggest that elevation can be a useful surrogate to look at the long-term effect of environmental change (e.g., climatic change) on freshwater biotic communities of the Precambrian Shield.

\section{Methods}

Study area

Streams were located from Georgian Bay- Massassauga Provincial Park to Algonquin Provincial Park with a rapid elevation increase extending from 180 to $472 \mathrm{~m}$ at $45^{\circ} \mathrm{N}$ on the Canadian Precambrian Shield (Fig. 1). Based on the region's topography, three headwater streams in Algonquin Provincial Park (i.e., D1, G1, and E1) were chosen at higher elevation. Two streams in Arrowhead Park (E2 and F1) and an additional stream near Harp Lake, Dorset (HP3A) were chosen at mid elevation. At the lower elevations, a stream in Massasauga Provincial Park (H1) and a stream in the District of Parry Sound (H2) were chosen. Period of the 


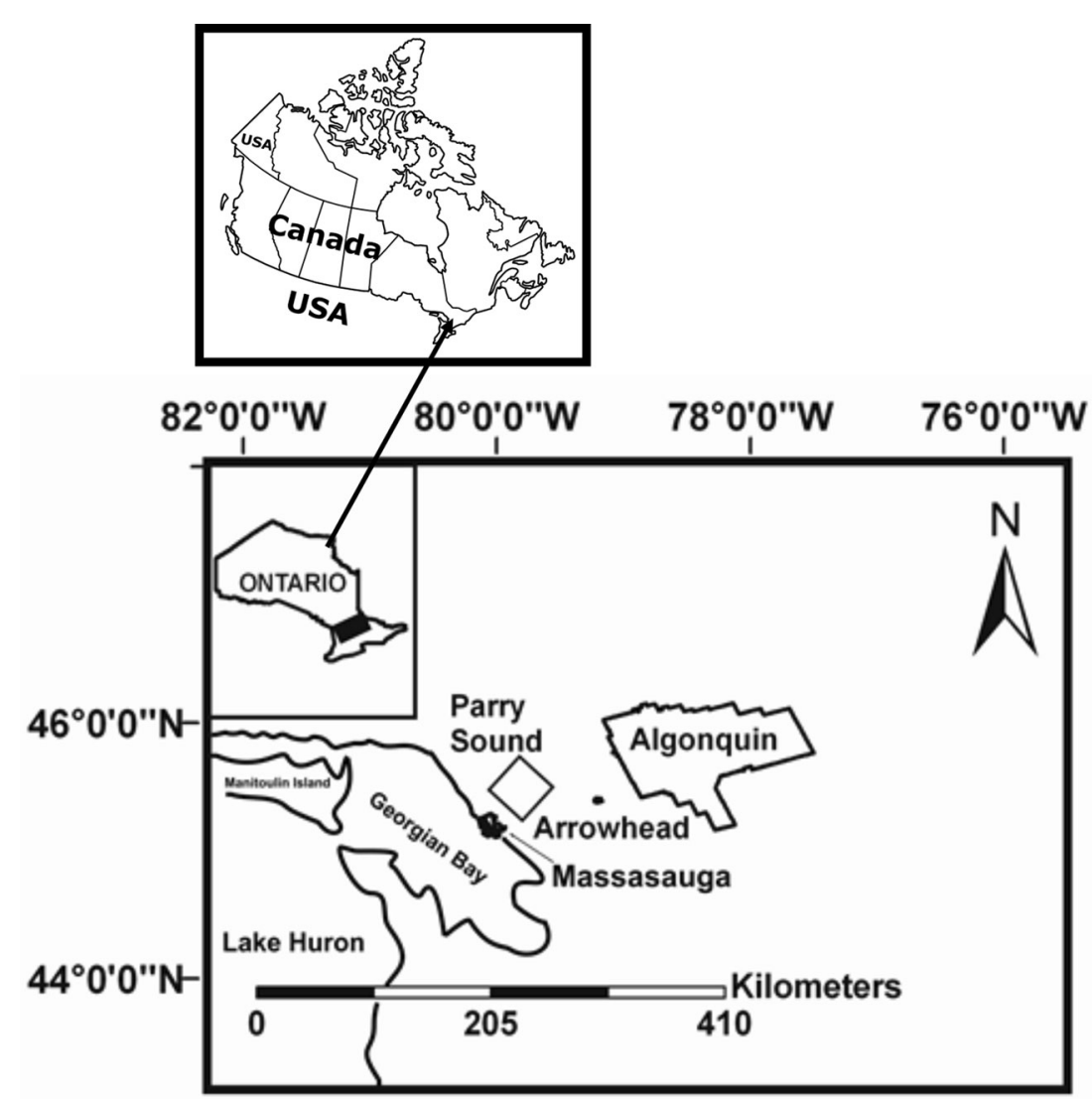

Fig. 1 Location of study streams in Precambrian shield, Ontario, Canada, 2010-2011

samplings was based on the start of the freshet each year, accessibility to the streams after the freshet, and also the time when streams dry up (i.e., presence of flow). The corridor from Massassauga to Algonquin sits on metamorphic bedrock with thin top soil layer. Streams were all fishless.

Sampling benthic invertebrates

Monthly samples of benthic invertebrates were obtained between April-July 2010 and May-July 2011 using a small net with a flexible frame and a mesh size of $250 \mu \mathrm{m}$. Samples were collected by walking along the width of the stream, vigorously kicking the substrate to disturb it to a depth of $\sim 5 \mathrm{~cm}$ for about $3 \mathrm{~min}$. Samples were collected from one reach (i.e., two riffles and one pool). In all streams, pools and riffles are near each other, so that with exception of sedentary benthos (e.g., bivalves), most benthic species occur in both habitats. The mesh size, sampling procedure including the effort time, and habitat types were determined and standardized based on a pilot study that we conducted in the previous year (April-June 2009). Samples of benthos transported in $3 \mathrm{~L}$ whirl-packs and preserved in ethyl alcohol anhydrous solution (85.5\% ethanol and $13.7 \%$ methanol, and $0.85 \%$ ethyl acetate; ACP Chemical Inc). The benthos samples were sieved and sorted in the laboratory and all insects were identified to genera and species level. Individual species were subsequently placed in appropriate functional feeding groups based on Merrit et al. (2008) and Barbour et al. (1999). A detailed list and abundance of species collected are provided in Online Appendix 1.

Temperature and precipitation

Water and air temperatures were obtained using iBTag Alpha Mach Inc. temperature data loggers from April to July for 2010 and May to July at every $3 \mathrm{~h}$ interval for 2011, as no significant pattern of change were detected on hourly basis. For each study, stream two sets of loggers were installed: one at the designated reach 
and one monitoring the air temperature adjacent to the stream (i.e., attached to a tree adjacent to the designated reach). All the temperature loggers were synchronized, so that the air and the stream temperature recordings at all the elevations and streams were running simultaneously.

Degree day (DD) was calculated April-July 2010 and May-July 2011 based on accumulated temperature in each stream above $0{ }^{\circ} \mathrm{C}$ and below $16^{\circ} \mathrm{C}$. Poikilotherm development is best modelled using DD as the unit of temperature-time (Baskerville and Emin 1969; Beresford and Sutcliffe 2009). DD is defined as $1{ }^{\circ} \mathrm{C}$ per $24 \mathrm{~h}$ above some developmental threshold temperature. Based on the 2 years, our investigation and monitoring of the stream temperature we found that streams dry up as soon as water temperature exceeds $16{ }^{\circ} \mathrm{C}$ (i.e., being intermittent headwater streams), so we used the number of DD accumulated based on this measure to estimate the developmental threshold of benthos. In addition, since the streams dry up, there was a clear indication that ground water by means of water from the saturated zone had no influence on these streams or on their temperature (J.M. Buttle, School of Environment, Hydrology, Trent University-personal communication, November 05,2010$)$. We calculated mean monthly precipitation based on the data collected from the historical climate data of Environment Canada for Algonquin Provincial Park (streams D1, G1, and E1), Arrowhead Provincial Park (streams E2 and F1), Harp Lake, Dorset (stream HP3A), Massasauga Provincial Park (stream H1), and the District of Parry Sound (stream H2) (http://climate.weather.gc.ca/).

Chemical data

Stream pH and conductivity were measured monthly (April-July 2010, July 2011) using an Accumet AP85, Fisher Scientific Instrument. In addition, water samples were collected monthly for total phosphorus (TP) in $35 \mathrm{ml} \mathrm{p}$-tubes and for total nitrogen (TN) dissolved organic and inorganic carbon (DOC and DIC) in $500 \mathrm{ml}$ PET jars in 2010 and only in July for 2011 (Online Appendix 2). Chemical analyses were performed at the Dorset Environmental Science Centre, Dorset, Ontario or Trent University following the Ontario Ministry of Environment and Climate Change standard method (Sutey et al. 2015).

Data analysis

Ordinations of benthic community data were performed by non-metric multidimensional scaling (NMDS) based on the Bray-Curtis similarity index and were performed after fourth-root transformation to down weight the influence of dominant species and to normalize the data. The stress value function was used to assess the representations of NMDS solutions according to (Clark and Gorley 2015). The guideline indicates that a stress value of $<0.05$ gives an excellent representation with no misinterpretation. The significance of any discrimination between sites was tested using analysis of similarity (ANOSIM) test with $R$ ranging from -1 to 1 at $\alpha=0.05$. Similarity percentage test (SIMPER) was used to calculate the contribution of individual species to similarity or dissimilarity between streams. NMDS analyses were performed using PRIMER v 7 (Clark and Gorley 2015).

A detrended correspondence analysis (DCA) of benthic communities was performed for 2010-2011. This was done to determine whether species have a linear or a unimodal distribution and to determine what ordination analysis is appropriate to correlate benthos abundance data with environmental variables. For each DCA analyses, we down-weighted the rare species. Based on the first axis lengths gradient of DCA in 2010 (i.e., 1.4), species had a linear distribution. Therefore, redundancy analyses (RDA) were used to correlate the communities of species in 2010 (May-July) to environmental variables (i.e., chemicals, water temperature, DD, precipitations, and catchment area). Result of first axis length gradient of DCA for July 2011 was inconclusive (i.e., 2.2); therefore, canonical correspondence analysis (CCA) and RDA were used to correlate July benthic data to July environmental data. For each set of RDAs and CCAs, we sequentially removed variables with high inflation rate (i.e., $>10$ ) and a Monte-Carlo permutation test (999 unrestricted permutation) was ran to account for the variables that significantly (i.e., $P<0.05$ ) contribute to the species variations. A correspondence analysis (CA) was performed on the benthos community 2010-2011. The first and second CA axis (CA1 and CA2) scores (i.e., for streams) obtained were correlated with environmental variable(s) that significantly accounted for variation in benthic communities along the elevation gradient. This will determine if the environmental variable correlates with the variation of benthic community in streams and whether this is elevational dependent. We fourth-root transformed the species relative abundance and 
normalized the environmental variables before these ordination analyses. The CANOCO for Windows 4.5 (ter Braak and Šmilauer 2002) was used for DCA, RDA, and CCA. CA analyses was conducted in PAST v 2.14 (Hammer et al. 2001). Species codes are provided in Online Appendix 3.

Following the ordination analyses of communities, a two-way ANOVA (i.e., difference in elevation and month) was performed in PAST v 2.14 (Hammer et al. 2001) on the communities' richness, Shannon-Weaver Diversity $\left(H^{\prime}\right)$, evenness, and FFGs. A two-way ANOVA was also used to compare the chemical variables between streams at different elevations in 2010. For 2011, only the July pH, TP, and TN data were available which we compared using a one-way ANOVA. In addition, linear regressions were performed to predict the effect of air temperature on stream temperature variation, 2010-2011. This analysis will determine whether change in air temperature along the elevation will influence the streams temperature variation. Analysis for each year was kept separate to determine if similar trend of variation (i.e., both biotic and abiotic) along the elevation can be detected.

\section{Results}

Environmental variables and variations in community data

The 2010-2011 DD accumulated was higher in higher elevation streams compared to those at lower (Table 1). The 2010 air temperature regression with streams temperature produced $R^{2}$ value of 0.86 , which was significant $\left(F_{1,30 d f}=186.4, P<0.001\right)$. The 2011 air temperature regression with stream temperature produced $R^{2}$ value of 0.75 , which was significant $\left(F_{1,22 d f}=64.6, P<0.001\right)$. This result indicates that change in air temperature along the elevation can account for variation in stream temperature.

Stepwise backwards elimination in RDA retained DD, catchment area, and water temperature as variables that were correlated with benthic communities in 2010 (April-July; Fig. 2a). Water temperature was the only factor in 2010 that significantly correlated with the communities $(P=0.03)$. CCA explained greater amounts of species variation in July 2011 compared to RDA (29.9 vs. 23.4\%). Therefore, CCA results are presented here. Stepwise backward elimination in CCA retained catchment area, TP, TN, and water temperature as variables that were correlated with benthic communities in July 2011 (Fig. 2b). Water temperature was the only factor in July 2011 that significantly correlated with communities $(P=0.002)$. In 2010, CA1 did not significantly correlate with temperature $(R=-0.225)$; however, CA2 significantly correlated with temperature $(R=0.557)$. For 2011 , both CA1 and CA2 significantly correlated with stream temperature $(R=-0.67$ and $R=0.78$ ). Results of the correspondence analysis are provided in Online Appendix 4.

Results of two-way ANOVA showed all FFG significantly differed between elevations in 2010 (Table 2A). Shannon-Weaver diversity index, evenness, and both CA1 and CA2 also differed significantly in 2010. However, richness did not vary significantly (Table 2A). Similar results were obtained for 2011 for FFG,

Table 1 Study streams' geographical location, elevation, location in Ontario Provincial Parks or district, mean DD accumulated \pm SD, and mean stream temperature \pm SD for April-July 2010 and May-July 2011

\begin{tabular}{lllllllll}
\hline Streams & Latitude & Longitude & $\begin{array}{l}\text { Elevation } \\
(\mathrm{m})\end{array}$ & $\begin{array}{l}\text { Provincial } \\
\text { park/ } \\
\text { district }\end{array}$ & $\begin{array}{l}\text { DD April- } \\
\text { July 2010 }\end{array}$ & $\begin{array}{l}\text { DD May- } \\
\text { July 2011 }\end{array}$ & $\begin{array}{l}\text { Temperature } \\
\text { April-July } \\
2010\end{array}$ & $\begin{array}{l}\text { Temperature } \\
\text { May-July } \\
2011\end{array}$ \\
\hline $\mathrm{D} 1$ & $45^{\circ} 27^{\prime} 03^{\prime \prime} \mathrm{N}$ & $78^{\circ} 48^{\prime} 05^{\prime \prime} \mathrm{W}$ & 472 & Algonquin & $84.5 \pm 11.2$ & $23.6 \pm 12.0$ & $11.4 \pm 3.2$ & $12.9 \pm 2.4$ \\
$\mathrm{G} 1$ & $45^{\circ} 28^{\prime} 16^{\prime \prime} \mathrm{N}$ & $78^{\circ} 48^{\prime} 17^{\prime \prime} \mathrm{W}$ & 445 & Algonquin & $113.8 \pm 4.3$ & $28.2 \pm 4.1$ & $11.3 \pm 3.1$ & $12.2 \pm 2.0$ \\
$\mathrm{E} 1$ & $45^{\circ} 28^{\prime} 42^{\prime \prime} \mathrm{N}$ & $78^{\circ} 48^{\prime} 55^{\prime \prime} \mathrm{W}$ & 425 & Algonquin & $110.5 \pm 3.9$ & $28.0 \pm 4.4$ & $10.7 \pm 3.4$ & $11.3 \pm 2.1$ \\
$\mathrm{E} 2$ & $45^{\circ} 25^{\prime} 51^{\prime \prime} \mathrm{N}$ & $79^{\circ} 11^{\prime} 17^{\prime \prime} \mathrm{W}$ & 373 & Arrowhead & $112.4 \pm 4.1$ & $27.7 \pm 4.9$ & $10.9 \pm 3.3$ & $11.6 \pm 2.3$ \\
$\mathrm{HP} 3 \mathrm{~A}$ & $45^{\circ} 22^{\prime} 24^{\prime \prime} \mathrm{N}$ & $79^{\circ} 08^{\prime} 56^{\prime \prime} \mathrm{W}$ & 362 & Muskoka & $75.5 \pm 11.6$ & $22.0 \pm 12.9$ & $11.8 \pm 3.1$ & $13.5 \pm 1.7$ \\
$\mathrm{~F} 1$ & $45^{\circ} 23^{\prime} 52^{\prime \prime} \mathrm{N}$ & $79^{\circ} 11^{\prime} 35^{\prime \prime} \mathrm{W}$ & 337 & Arrowhead & $75.4 \pm 11.0$ & $21.0 \pm 12.3$ & $12.0 \pm 3.4$ & $13.2 \pm 2.1$ \\
$\mathrm{H} 2$ & $45^{\circ} 13^{\prime} 27^{\prime \prime} \mathrm{N}$ & $79^{\circ} 43^{\prime} 34^{\prime \prime} \mathrm{W}$ & 240 & Parry sound & $58.6 \pm 8.2$ & $22.4 \pm 10.3$ & $12.8 \pm 2.6$ & $13.7 \pm 0.5$ \\
$\mathrm{H} 1$ & $45^{\circ} 07^{\prime} 29^{\prime \prime} \mathrm{N}$ & $79^{\circ} 59^{\prime} 52^{\prime \prime} \mathrm{W}$ & 185 & Massasauga & $58.6 \pm 8.2$ & $13.7 \pm 9.3$ & $12.8 \pm 2.6$ & $14.4 \pm 1.6$ \\
\hline
\end{tabular}



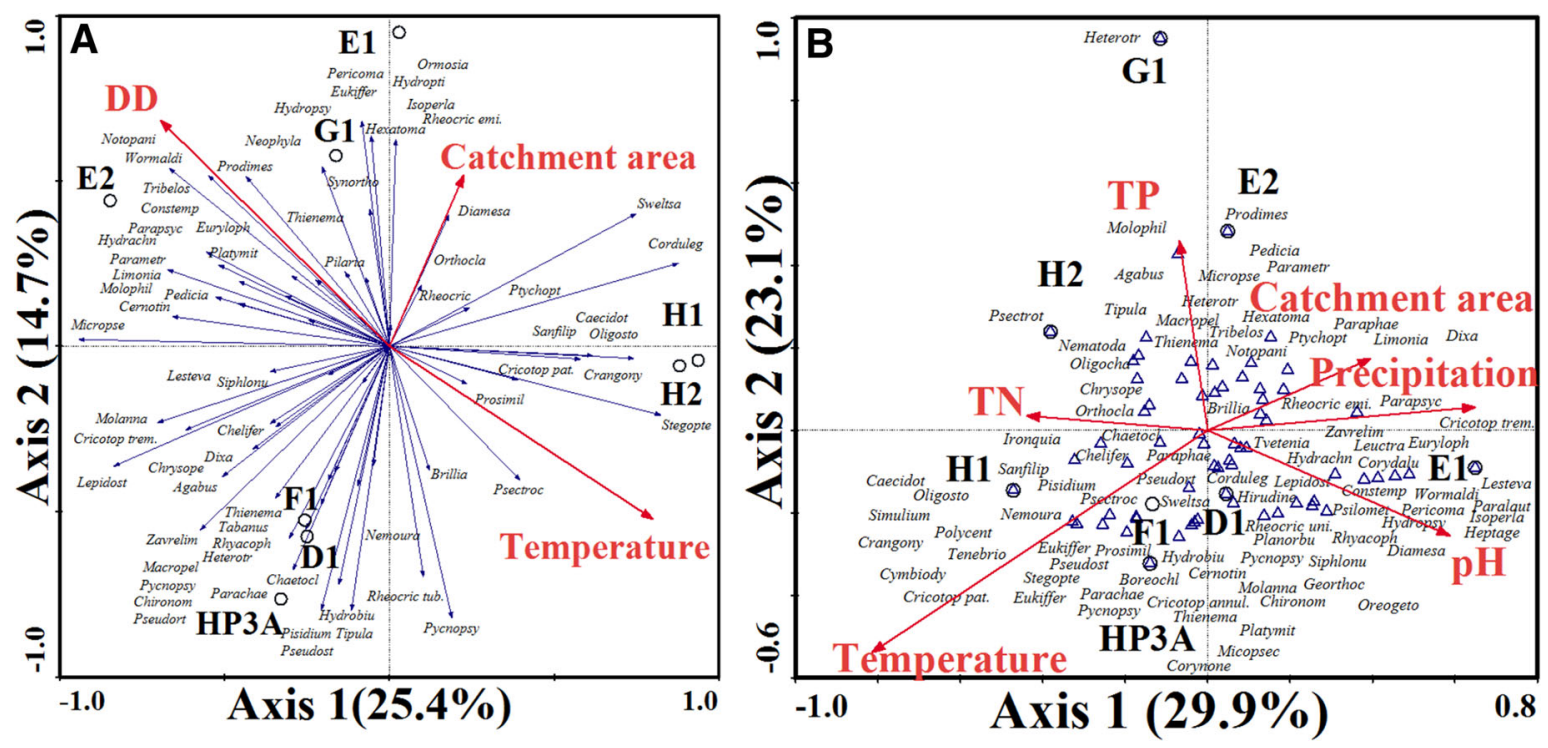

Fig. 2 Redundancy and canonical correspondence analyses of benthic communities and environmental variables, 2010-2011 a RDA April-July 2010 b CCA July 2011. Circles are study sites, and blue arrows (RDA) and triangles (CCA) are species, and red arrows are environmental variables

Table 2 Two-way ANOVA results of community variables, (A) April-July 2010 (B) May-July 2011

\begin{tabular}{|c|c|c|c|c|c|c|c|c|c|c|c|c|}
\hline \multirow[t]{3}{*}{ Variables } & \multicolumn{6}{|c|}{ (A) 2010} & \multicolumn{6}{|c|}{ (B) 2011} \\
\hline & \multicolumn{2}{|c|}{ Elevation (8) } & \multicolumn{2}{|c|}{ Month (4) } & \multicolumn{2}{|c|}{ Interaction } & \multicolumn{2}{|c|}{ Elevation (8) } & \multicolumn{2}{|c|}{ Month (3) } & \multicolumn{2}{|c|}{ Interaction } \\
\hline & $F$ & $P$ & $F$ & $P$ & $F$ & $P$ & $F$ & $P$ & $F$ & $P$ & $F$ & $P$ \\
\hline Shredders & 14.3 & $<0.001$ & 271.6 & $<0.001$ & 14.3 & $<0.001$ & 17.9 & $<0.001$ & 332.2 & $<0.001$ & 17.6 & $<0.001$ \\
\hline Collector filterers & 14.0 & $<0.001$ & 255.4 & $<0.001$ & 14.4 & $<0.001$ & 17.9 & $<0.001$ & 318.9 & $<0.001$ & 17.5 & $<0.001$ \\
\hline Collector gatherers & 14.4 & $<0.001$ & 248.9 & $<0.001$ & 14.2 & $<0.001$ & 17.2 & $<0.001$ & 330.0 & $<0.001$ & 18.2 & $<0.001$ \\
\hline Scrapers & 14.5 & $<0.001$ & 287.6 & $<0.001$ & 14.3 & $<0.001$ & 17.9 & $<0.001$ & 364.6 & $<0.001$ & 18.0 & $<0.001$ \\
\hline Predators & 14.7 & $<0.001$ & 259.5 & $<0.001$ & 13.9 & $<0.001$ & 17.7 & $<0.001$ & 301.3 & $<0.001$ & 17.0 & $<0.001$ \\
\hline Parasites & 14.4 & $<0.001$ & 290.5 & $<0.001$ & 14.4 & $<0.001$ & 18.0 & $<0.001$ & 364.7 & $<0.001$ & 18.0 & $<0.001$ \\
\hline Shannon-Weaver $H^{\prime}$ & 12.5 & $<0.001$ & 88.8 & $<0.001$ & 14.1 & $<0.001$ & 10.5 & $<0.001$ & 92.1 & $<0.001$ & 14.6 & $<0.001$ \\
\hline Evenness & 14.1 & $<0.001$ & 241.3 & $<0.001$ & 14.5 & $<0.001$ & 16.9 & $<0.001$ & 298.5 & $<0.001$ & 18.2 & $<0.001$ \\
\hline Richness & 1.6 & 0.14 & 240.1 & $<0.001$ & 2.4 & 0.01 & 1.5 & 0.2 & 183.4 & $<0.001$ & 1.9 & 0.05 \\
\hline CA1 & 17.2 & $<0.001$ & 262.1 & $<0.001$ & 11.8 & $<0.001$ & 15.1 & $<0.001$ & 160.6 & $<0.001$ & 7.4 & $<0.001$ \\
\hline CA2 & 12.8 & $<0.001$ & 237.9 & $<0.001$ & 11.7 & $<0.001$ & 16.1 & $<0.001$ & 283.4 & $<0.001$ & 13.5 & $<0.00$ \\
\hline
\end{tabular}

The number of months and elevation sites (i.e., streams) is in the brackets

Shannon-Weaver diversity index $\left(H^{\prime}\right)$, evenness, and CA1 and CA2, and richness did not significantly vary again (Table 2B).

Based on the results of the two-way ANOVA water temperature significantly differed between streams at different elevations (i.e., lower to higher elevations) in 2010. However, precipitation did not vary significantly in 2010 (Table 3A). Result of the two-way ANOVA indicates that for 2010, all water chemistry variables were significantly different between streams at different elevations (Table 3A). Results of the 2011 two-way ANOVA water temperature showed significant difference between streams at different elevations. However, precipitation did not vary significantly in 2011 (Table 3B). Result of the one-way ANOVA indicates that July 2011 water chemistry variables did not vary significantly between streams at different elevations (Table 3B). 
Table 3 (A) Two-way ANOVA results of environmental variables, April-July 2010. (B) Two-way ANOVA results of temperature and precipitation May-July 2011 and one-way ANOVA of July 2011 chemical variables

\begin{tabular}{|c|c|c|c|c|c|c|c|c|c|c|c|c|}
\hline \multirow[t]{3}{*}{ Variables } & \multicolumn{6}{|c|}{ (A) 2010} & \multicolumn{6}{|c|}{ (B) 2011} \\
\hline & \multicolumn{2}{|c|}{ Elevation (8) } & \multicolumn{2}{|c|}{ Month (4) } & \multicolumn{2}{|c|}{ Interaction } & \multicolumn{2}{|c|}{ Elevation (8) } & \multicolumn{2}{|c|}{ Month (3) } & \multicolumn{2}{|c|}{ Interaction } \\
\hline & $F$ & $P$ & $F$ & $P$ & $F$ & $P$ & $F$ & $P$ & $F$ & $P$ & $F$ & $P$ \\
\hline $\mathrm{pH}$ & 12.9 & $<0.001$ & 215.2 & $<0.001$ & 15.4 & $<0.001$ & 0.91 & 0.55 & - & - & - & - \\
\hline $\mathrm{DOC}(\mathrm{mg} / \mathrm{L})$ & 2.5 & 0.02 & 7.2 & $<0.001$ & 1.2 & 0.29 & - & - & - & - & - & - \\
\hline DIC (mg/L) & 7.3 & $<0.001$ & 11.3 & $<0.001$ & 2.6 & $<0.001$ & - & - & - & - & - & - \\
\hline $\mathrm{TP}(\mu \mathrm{g} / \mathrm{L})$ & 1.6 & 0.16 & 6.0 & $<0.001$ & 1.6 & 0.1 & 0.96 & 0.52 & - & - & - & - \\
\hline $\mathrm{TN}(\mu \mathrm{g} / \mathrm{L})$ & 13.7 & $<0.001$ & 227.5 & $<0.001$ & 13.4 & $<0.001$ & 1.0 & 0.49 & - & - & - & - \\
\hline Conductivity $(\mu \mathrm{S} / \mathrm{cm})$ & 30.6 & $<0.001$ & 351.9 & $<0.001$ & 28.3 & $<0.001$ & - & - & - & - & - & - \\
\hline Temperature $\left({ }^{\circ} \mathrm{C}\right)$ & 3.3 & 0.005 & 164.7 & $<0.001$ & 1.4 & 0.16 & 3.9 & 0.002 & 261.6 & $<0.001$ & 1.9 & 0.05 \\
\hline Precipitation $(\mathrm{mm})$ & 0.3 & 0.94 & 123.2 & $<0.001$ & 0.34 & 0.99 & 0.1 & 0.99 & 127.6 & $<0.001$ & 0.03 & 0.99 \\
\hline
\end{tabular}

The number of months and elevation sites (i.e., streams) is in the brackets

$D O C$ dissolved organic carbon, DIC dissolved inorganic carbon, $T P$ total phosphorus, $T N$ total nitrogen

Community data 2010-2011

NMDS ordination of 2010 abundance data (April-July) in two-dimensional space yielded a clear separation between streams (stress value 0.04). Streams E2, F1, and HP3A and D1 sit in center of biplot; E1 at bottomleft and $\mathrm{G} 1$ at middle-top of biplot; $\mathrm{H} 1$ and $\mathrm{H} 2$ at right of the biplot (Fig. 3a). One-way nested ANOSIM yields a significant difference between benthic communities at different elevations (global test $R=0.380$, $P=0.001$ ). Pairwise ANOSIM test indicates that D1 and E1 are significantly different from $\mathrm{H} 1$ and $\mathrm{H} 2$ (global test $R_{\mathrm{D} 1-\mathrm{H} 1}=0.854, P_{\mathrm{D} 1-\mathrm{H} 1}=0.03 ; R_{\mathrm{D} 1-\mathrm{H} 2}=0.635, P_{\mathrm{D} 1-\mathrm{H} 2}=0.03 ; R_{\mathrm{E} 1-\mathrm{H} 1}=0.896, P_{\mathrm{D} 1-\mathrm{H} 1}=0.03$; $R_{\mathrm{E} 1-\mathrm{H} 2}=0.833, P_{\mathrm{E} 1-\mathrm{H} 2}=0.03$ ). E2 and F1 significantly differed from $\mathrm{H} 1$ and $\mathrm{H} 2$ (global test $R_{\mathrm{E} 2-\mathrm{H} 1}=0.729$, $P_{\mathrm{E} 2-\mathrm{H} 1}=0.03 ; R_{\mathrm{E} 2-\mathrm{H} 2}=0.635, P_{\mathrm{E} 2-\mathrm{H} 2}=0.03 ; R_{\mathrm{F} 1-\mathrm{H} 1}=0.688, \quad P_{\mathrm{F} 1-\mathrm{H} 1}=0.03 ; R_{\mathrm{F} 1-\mathrm{H} 2}=0.479, \quad P_{\mathrm{F} 1-\mathrm{H} 2-}$ $=0.03$ ). HP3A significantly differed from H1 (global test $R=0.573, P=0.03$ ). NMDS ordination of 2011 abundance data (stress value 0.04) in two-dimensional space yielded a clear separation between streams that are located at high and mid elevations (i.e., D1, G1, E1, E2, HP3A, and F1) from those at the lower elevation (i.e., H1 and H2). The 2011 result was similar to 2010; however, stream F1 sit closer to H2 (Fig. 3b). One-way nested ANOSIM yield a significant difference between benthic communities at different elevations (global test $R=0.496, P=0.001)$. Pairwise ANOSIM test for 2011 was slightly different. E1 and G1 were significantly different from H1 (global test $R_{\mathrm{E} 1-\mathrm{H} 1}=0.926, P_{\mathrm{D} 1-\mathrm{H} 1}=0.03 ; R_{\mathrm{G} 1-\mathrm{Ha}}=0.778, P_{\mathrm{G} 1-\mathrm{H} 1}=0.03$ ).

Based on the 2010 results of SIMPER test on benthic communities, the highest dissimilarity was between streams E1 and H1 (SIMPER average dissimilarity $=72.0 \%$ ) with top five contributor species Crangonyx sp. (5.2\%), Caecidotea sp. (4.4\%), Prosimulium sp. (4.1\%), Parapsyche apicalis (4.0\%), and Notopanisus sp. (3.8\%). Streams G1 and H1 showed the second highest dissimilarity (SIMPER average dissimilarity $=71.6 \%$ )

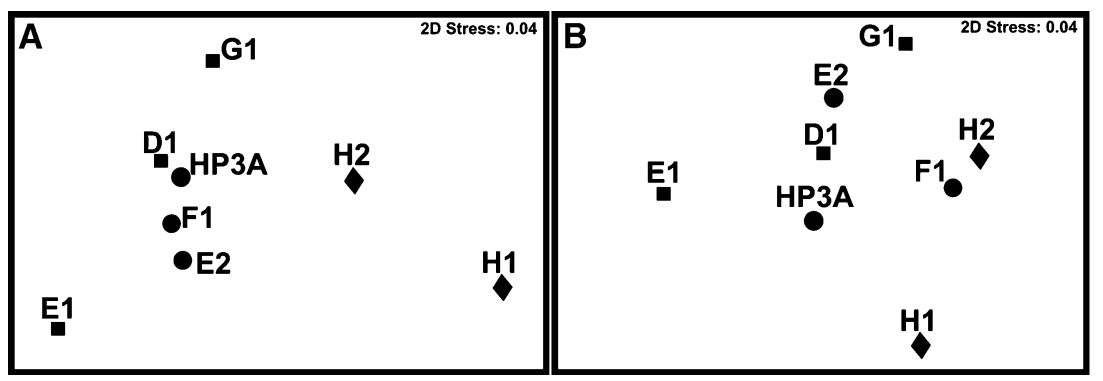

Fig. 3 Non-metric multidimensional scaling analyses of benthic communities, 2010-2011 a April-July 2010 b May-July 2011. Diamonds are lower elevation streams $(185-240 \mathrm{~m})$, circles are mid elevation streams $(337-373 \mathrm{~m})$, and squares are higher elevation streams $(425-472 \mathrm{~m})$ 
with top five contributor species being Crangonyx sp. (7.3\%), Caecidotea sp. (6.2\%), Micropsectra polita (5.5\%), Prosimulium sp. (5.5\%), and Sweltsa naica (3.9\%). Results of SIMPER test for 2011 were slightly different. The highest dissimilarity was between streams E1 and F1 (SIMPER average dissimilarity $=73.0 \%$ ) with top five contributor species Siphlonurus marshalli (3.4\%), Isoperla richardsoni (3.1\%), Parametriocnemus lundbeckii (2.7\%), Micropsectra polita (2.5\%), and Sweltsa naica (2.4\%). Streams E1 and H1 had the second highest dissimilarity (SIMPER average dissimilarity $=67.5 \%$ ) with top five contributor species Simulium sp. (4.1\%), Nemoura trispinosa (3.7\%), Crangonyx sp. (3.1\%), Thienemannimyia group (3.1\%), and Siphlonurus marshalli (3.0\%).

\section{Discussion}

Delineating the effect of temperature

In this study, streams of similar size and same order were chosen, and in addition, we eliminated or minimized the effect of the predatory fish, bedrock geology and ground water influence to limit the local environmental variables that may obscure the effect of elevation. Therefore, due to close geographical proximity (i.e., $<100 \mathrm{~km}$ ) and similarity in habitats (i.e., first-order streams in mixed-deciduous forest), much of the community differences can be inferred to be caused by elevation, with any differences in the hydrological properties of the streams (e.g., order: substratum, size) having minimal effect on benthic communities' composition. This argument is further supported by the fact that the variation in the different stream communities was mainly attributed to differences in temperature between streams. Parameters such as water chemistry and catchment area did not explain the observed community variations. We also found that changes in air temperature along the elevation gradient accounted for variations in stream temperature. Given that precipitation (i.e., another climatic factor) did not vary with elevation, we argue that any changes in air temperature due to elevation directly influence stream temperature.

From this, we infer that temperature associated with elevation can account for differences in abundance, diversity and FFG of communities. This is supported by the results of the 2010-2011 pairwise ANOSIM and SIMPER analyses, which indicate that the main differences in benthic communities were between high and low elevation streams, with the greatest difference accounted by cold-stenothermic species, e.g., insects such as Plecoptera species Sweltsa naica, Nemoura trispinosa and Isoperla richardsoni, Ephemeroptera species Siphlonurus marshalli, Trichoptera species Parapsyche apicalis, and Diptera species Prosimulium sp., Simulium sp., Parametriocnemus lundbeckii and Micropsectra polita. Haidekker and Hering (2008) have previously shown that in small streams with differences of up to $3{ }^{\circ} \mathrm{C}$, cold-stenothermic insects can account for majority of the variation in benthic communities. Given that mean April-July 2010 and May-July 2011, temperature difference between high and low elevation streams (i.e., E1, D1, G1, and H1 and H2) was 2.1 and $3.1{ }^{\circ} \mathrm{C}$, respectively, it appears that only the higher elevations had streams close with optimal temperature condition (i.e., cooler) for high benthic insect abundance and diversity.

Distinguishing the effect of water temperature on communities of streams benthos from other environmental variables (i.e., physical and chemical) is a challenging task. This is especially true if streams are of different size, depth, flow, and substrate types (Arai et al. 2015; Duggan et al. 2007; Phillips et al. 2015; Quinn and Hickey 1990; Statzner and Higler 1986). Headwater streams naturally control for many confounding factors as they have significantly lower or no anthropogenic impact and lower variation in flow regimes and water quality year around (Arai et al. 2015; Cummins 1974; Karr and Dudley 1981; Moore and Wondzell 2005; Richardson and Danehy 2007). Therefore, temperature plays a significant role for benthic invertebrates of headwater streams (Arai et al. 2015; Chang et al. 2012). For example, few eurythermic species are found in headwater streams in general (Haidekker and Hering 2008). Increasing a stream's temperature can have a significant impact on physiology, ecology, and life history of organisms living in streams (Angilletta 2009; Sheldon and Tewksbury 2014a, b). We are still at the preliminary stage of understanding of how temperature change shifts the communities in freshwaters as a whole and in long term. Moreover, consensus on how this change occurs varies perhaps due to differences in geographical regions, scale of the study and type of the freshwaters. In this study, data are only suggestive that temperature accounts for variation among community 
of benthos (i.e., based on the CA analysis species scores correlation with stream temperature, RDA and CCA analyses, DD, and temperature data).

Intermittent nature of the streams, flow regime, and drawbacks

The intermittent natures of the streams in addition to their inaccessibility were major drawbacks in our study. This means that many routine or daily measurements such as water chemistry, DO, and flow regime were not obtainable throughout the sampling season. The year around flow of the streams has influence on abundance and function of benthic communities (Boulton and Lake 1988; Hose et al. 2005), yet cannot be determined with certainty in this study. In the 2010, freshet started in April and stream flow lasted until late July with all streams at higher elevation (i.e., D1, G1, and E1) and those at mid elevation (i.e., E2, HP3A, and F1) having flow during this period. However, in 2011, freshet started in mid-May and stream flow lasted until mid-July with many streams experiencing (i.e., at all elevations) drought after this period. These combined with the 2 year accumulated DD indicate that streams at mid-to-high elevation dry up much later in summer compared to those of lower elevation which further could indicate a prolonged period of drought for the latter. Given that precipitation did not significantly varied between streams, we can suggest that difference of air temperature driven by difference in elevation may accounts for considerable variation in flow regimes as well. That is if we exclude the influence of the ground water or subsurface flow which were minimized in this study. Therefore, at least for the summer months when the community data are obtained we can expect a lower community measures such as abundance, diversity, and functional differences in low elevation streams compared to those at mid-higher elevation. Results of DD and temperature data suggest that streams water at lower elevations evaporate faster than those in mid-higher elevation. Furthermore, similarity of benthic community of stream F1 located at mid elevation (at lower range for this elevation) to stream at low elevation in 2011 suggests that during prolonged low flow regimes, streams at mid-higher elevation can eventually resemble those of the low elevation. This is because shorter growth periods for benthos can limits their resources such as food, timing of emergence, and synchrony of emergence among competing species (Hynes 1958; Boulton 2003; Cowx et al. 1984) and hence limit space and time for many benthic invertebrates. Therefore, based on the 2010-2011 results of abundance, diversity, and FFG, we can only suggest that higher elevation streams provide a better condition for insect's growth and colonization during the months that optimal conditions are not obtainable in lower elevations. This also suggests that flow regime change in this region will be more detectable for streams of lower elevation. However, further increase in temperature and drought can eventually impact streams at higher elevations as well.

\section{Elevation and community of benthos}

Past studies in their accounting the community differences of invertebrate communities along elevation gradient (e.g., Huey 1978, Jacobsen et al. 1997; Jacobsen 2003, 2004; Lawton et al. 1987; MacArthur 1972; McCoy 1990; Stevens 1992; Scheibler et al. 2014; Vinson and Hawkins 1998) have used large elevations (i.e., $\gg 100 \mathrm{~m}$ of difference). These studies in general encountered communities with different taxonomic groups stretched along large elevation. However, in this study, communities are stretched over a short elevation gradient (i.e., $287 \mathrm{~m}$ of difference). Therefore, the difference in communities is mainly driven by the change in abundance of benthos along the elevation, and not necessarily driven by different taxonomically structured communities (Hughes et al. 2008). Therefore, for geographical areas such as the Precambrian Shield of Canada which large elevation gradient is not obtainable, task of discriminating communities of benthic invertebrates should rely on this abundance difference and probably lowest possible taxonomic identification of benthos (i.e., genus and species) is also required.

The 2010-2011 result obtained from richness did not produce a support for our objectives of showing difference in communities of benthos along a short elevation gradient. The fact that richness did not significantly vary among the streams is due to the fact that the difference in communities is not based on difference in the number of taxonomically different species but on differences in abundance. An effect on richness per se might be found across a larger elevation gradient (e.g., Jacobsen 2003; McCoy 1990; Monoghan et al. 2000; Ramírez and Pringle 1998; Stout and Vandermeer 1975). We found that only the abundance of different FFG varies between streams of different elevation and not the type of FFG which further indicates that communities 
are not taxonomically different. Therefore, result of the richness obtained in this study is not comparable with other studies having large elevation gradients (e.g., Jacobsen 2003; McCoy 1990; Monoghan et al. 2000; Ramírez and Pringle 1998; Stout and Vandermeer 1975), so that variation in abundance (i.e., species and FFG) and diversity is better measures for community difference compared to richness using low elevation gradients. Richness, however, varied monthly within and between streams. Therefore, we can assume that certain taxa could locally go extinct during the months that streams dry up or harsh stream conditions (e.g. high temperature) sets in. This also means that populations of these species can thrive in other elevations with suitable environmental conditions (i.e., via migration). Many benthic invertebrates in this study streams (i.e., insects) have high natural dispersal capability and, therefore, capable of rapid colonization of other waters.

In this study, we showed that difference between benthic invertebrate communities of several physicochemically comparable head water streams stretched along a short elevation gradient can be detected. The variation among benthic communities was mainly based on their abundance, FFG and diversity and not richness. Furthermore, among several obtainable and measured physico-chemical variables, stream temperature associated with altitudinal difference accounted significantly for the variation among benthos. Therefore, effects of change in environmental variables (e.g., temperature) on freshwater communities, associated with short elevational difference, can be inferred and used as a proxy for anticipated environmental change (e.g., climate) over time.

Acknowledgements We thank the personnel at Ontario Provincial Parks (MNRF), all the personnel in Wildlife Research Station, Algonquin Provincial Park, the summer students in Dr. Dillon's lab, and the staff of Ontario Ministry of the Environment, Dorset Environmental Science Centre. And finally, we thank Dr. D. Currie of Royal Ontario Museum and University of Toronto. Financial support for the project was provided by Ontario Ministry of Environment through a grant to Dr. Peter Dillon, Trent University.

Open Access This article is distributed under the terms of the Creative Commons Attribution 4.0 International License (http:// creativecommons.org/licenses/by/4.0/), which permits unrestricted use, distribution, and reproduction in any medium, provided you give appropriate credit to the original author(s) and the source, provide a link to the Creative Commons license, and indicate if changes were made.

\section{References}

Angilletta MJ (2009) Thermal adaptation: a theoretical and empirical synthesis. Oxford University Press, Oxford

Arai R, Nukazawa K, Kazama S, Takemon Y (2015) Variation in benthic invertebrate abundance along thermal gradients within headwater streams of a temperate basin in Japan. Hydrobiologia 762:55-63. https://doi.org/10.1007/s1075

Barbour MT, Gerristen J, Snyder BD, Stribling JB (1999) Rapid bioassessment protocols for use in streams and wadeable rivers: periphyton, benthic macroinvertebrates, and fish. US Environmental Agency Office of Water, Washington DC

Baskerville GL, Emin P (1969) Rapid estimation of heat accumulation from maximum and minimum temperatures. Ecology 50:514-517. https://doi.org/10.2307/1933912

Beresford DV, Sutcliffe JF (2009) Sampling designs of insect time series data: are they all irregularly spaced? Oikos 118:115-121. https://doi.org/10.1111/j.1600-0706.2008.16883.x

Boulton AJ (2003) Parallels and contrasts in the effects of drought on stream macroinvertebrate assemblages. Freshw Biol 48:1173-1185. https://doi.org/10.1046/j.1365-2427.2003.01084.x

Boulton AJ, Lake PS (1988) Australian temporary streams—-some ecological characteristics. Verh Int Ver Theor Angew Limnol 23:1380-1383. https://doi.org/10.1080/03680770.1987.11898025

Camargo JA, DeJalon DG (1995) Assessing the influence of altitude and temperature on biological monitoring of freshwater quality: a preliminary investigation. Environ Monit Assess 35:227-238. https://doi.org/10.1007/BF00547634

Carter JL, Fend SV, Kennelly SS (1996) The relationships among three habitat scales and stream benthic invertebrate community structure. Freshw Biol 35:109-124. https://doi.org/10.1046/j.1365-2427.1996.d01-450.x

Chang H, Jung IW, Steele M, Gannett M (2012) Spatial patterns of March and September streamflow trends in Pacific Northwest streams, 1958-2008. Geogr Anal 44: 177-201. https://doi.org/10.1111/j.1538-4632.2012.00847.x

Clark KR, Gorley RN (2015) PRIMER v7: user manual/tutorial. PRIMER-E, Plymouth, p 296

Cowx IG, Young WO, Hellawell JM (1984) The influence of drought on fish and invertebrate populations of an upland stream in Wales. Freshw Biol 14:165-177. https://doi.org/10.1111/j.1365-2427.1984.tb00030.x

Cummins KW (1974) Structure and function of stream ecosystems. Bioscience 24:631-641. https://doi.org/10.2307/1296676

Duggan I, Boothroyd I, Speirs D (2007) Factors affecting the distribution of stream macroinvertebrates in geothermal areas: Taupo Volcanic Zone, New Zealand. Hydrobiologia 592:235-247. https://doi.org/10.1007/s10750-007-0748-9

Haidekker A, Hering D (2008) Relationship between benthic insects (Ephemeroptera, Plecoptera, Coleoptera, Trichoptera) and temperature in small and medium-sized streams in Germany: a multivariate study. Aqua Ecol 42:463-481. https://doi.org/10. 1007/s10452-007-9097-z 
Hammer, Ø, Harper, DAT, Ryan PD (2001) PAST: paleontological statistics software package for education and data analysis. Palaeontologia Electronica 4(1):9

Hawkins CP, Norris RH, Gerritsen J, Hughes RM, Jackson SK, Johnson RK, Stevenson RJ (2000) Evaluation of the use of landscape classification for the prediction of freshwater biota: synthesis and recommendation. J N Am Benthol Soc 19:541-556. https://doi.org/10.2307/1468113

Hose GC, Jones P, Lim RP (2005) Hyporheic macroinvertebrates in riffle and pool areas of temporary streams in south eastern Australia. Hydrobiologia 532:81-90. https://doi.org/10.1007/s10750-004-9016-4

Huey RB (1978) Latitudinal pattern of between-elevation faunal similarity: mountains might be higher in tropics. Am Nat 112:225-229. https://doi.org/10.1086/283262

Hughes JM, Schmidt DJ, McLean A, Wheatley A (2008) Population genetic structure in stream insects: what have we learned. In: Lancaster J, Briers RA (eds) Aquatic insects, Proceedings of the Royal Entomological Society's 24th Symposium, pp 268-288

Hynes HBN (1958) The effect of drought on the fauna of a small mountain stream in Wales. Verh Int Ver Limnol 46:823-833. https://doi.org/10.1080/03680770.1956.11895473

Jacobsen D (2003) Altitudinal changes in diversity of macroinvertebrates from small streams in the Ecuadorian Andes. Arch Hydrobiol 158(2):145-167. https://doi.org/10.1127/0003-9136/2003/0158-0145

Jacobsen D (2004) Contrasting patterns in local and zonal family richness of stream invertebrates along an Andean altitudinal gradient. Freshw Biol 49:1293-1305. https://doi.org/10.1111/j.1365-2427.2004.01274.x

Jacobsen D (2008) Tropical high-altitude streams. In: Dudgeon D (ed) Aquatic ecosystems: tropical stream ecology. Elsevier Science, London, pp 219-256

Jacobsen D, Schultz R, Encalada A (1997) Structure and diversity of stream invertebrate assemblages: the influence of temperature with altitude and latitude. Freshw Biol 38:247-261. https://doi.org/10.1046/j.1365-2427.1997.00210.x

Karr J, Dudley D (1981) Ecological perspective on water quality goals. Environ Manag 5:55-68. https://doi.org/10.1007/ BF01866609

Lawton JH, MacGarvin M, Heads PA (1987) Effects of altitude on the abundance and species richness of insect herbivores on bracken. J Anim Ecol 56:147-160. Stable URL: http://www.jstor.org/stable/4805

MacArthur RH (1972) Geographical ecology: patterns in the distributions of species. Harper and Row, New York

Magnuson JJ, Webster KE, Assel RA, Bowser CJ, Dillon PJ, Eaton JG, Evans HE, Fee EJ, Hall RI, Mortsch LR, Schindler DW, Quinn FH (1997) Potential effects of climate changes on aquatic systems: Laurentian Great Lakes and Precambrian Shield Region. Hydrol Process 11:825-871. https://doi.org/10.1002/(sici)1099-1085(19970630)11:8<825:aid-hyp509>3.0.co;2-g

McCoy ED (1990) The distribution of insects along elevational gradients. Oikos 58:313-322

Merrit RW, Cummins KW, Berg MB (2008) An introduction to aquatic insects of North America, 4th edn. Kendall/Hunt Publishing Company, Iowa

Minshall GW, Cummins KW, Petersen RC, Cushing CE, Bruns DA, Sedell JR, Vannote RL (1985) Developments in stream ecosystem theory. Can J Fish Aqua Sci 42:1045-1055. https://doi.org/10.1139/f85-130

Monoghan KA, Peck MR, Brewin PA, Masiero M, Zarate E, Turcotte P, Ormerod SJ (2000) Macroinvertebrate distribution in Ecuadorian hill streams: the effect of altitude and land use. Arch Hydrobiol 149:421-440

Moore RD, Wondzell SM (2005) Physical hydrology and the effects of forest harvesting in the Pacific Northwest: a review. J Am Water Res Assoc 41:753-784. https://doi.org/10.1111/j.1752-1688.2005.tb03770.x

Phillips ID, Pollock MS, Bowman MF, McMaster DG, Chivers DP (2015) Thermal alteration and macroinvertebrate response below a large Northern Great Plains Reservoir. J Gt Lakes Res 41:155-163. https://doi.org/10.1016/j.jglr.2015.07.005

Quinn J, Hickey C (1990) Characterization and classification of benthic invertebrate communities in 88 New Zealand rivers in relation to environmental factors New Zealand. J Mar Freshw Res 24:387-409. https://doi.org/10.1080/00288330.1990. 9516432

Ramírez A, Pringle CM (1998) Structure and production of a benthic insect assemblage in a neotropical stream. J N Am Benthol Soc 17:443-463. https://doi.org/10.2307/1468365

Ramírez A, Pringle CM, Wantzen KM (2008) Tropical stream conservation. In: Dudgeon D (ed) Aquatic ecosystems: tropical stream ecology. Elsevier Science, London, pp 285-304

Richardson JS, Danehy RJ (2007) A synthesis of the ecology of headwater streams and their riparian zones in temperate forests. For Sci 53:131-147

Scheibler EE, Debandi GO (2008) Spatial and temporal patterns in the aquatic insect community of a high-altitude Andean stream (Mendoza, Argentina). Aqu Insects 30:145-161. https://doi.org/10.1080/01650420701880974

Scheibler EE, Claps MC, Roig-Juñent SA (2014) Temporal and altitudinal variations in benthic macroinvertebrate assemblages in an Andean river basin of Argentina. J Limnol 73:92-108. https://doi.org/10.4081/jlimnol.2014.789

Schindler DW, Bayley SE, Parker BR, Beaty KG, Cruikshank DR, Fee EJ, Schindler EU, Stainton MP (1996) The effect of climate warming on properties of boreal lakes and streams at the Experimental Lake Area, northwestern Ontario. Limnol Ocean 41:1004-1017. https://doi.org/10.4319/lo.1996.41.5.1004

Sheldon KS, Tewksbury JJ (2014a) The impact of seasonality in temperature on thermal tolerance and elevational range size. Ecology 95:2134-2143. https://doi.org/10.1890/13-1703.1

Sheldon KS, Tewksbury JJ (2014b) The impact of seasonality in temperature on thermal tolerance and elevational range size. Ecology 95:2134-2143. https://doi.org/10.1890/13-1703.1

Statzner B, Higler B (1986) Stream hydraulics as a major determinant of benthic invertebrate zonation patterns. Freshw Biol 16:127-139. https://doi.org/10.1111/j.1365-2427.1986.tb00954.x

Stevens GC (1992) The elevational gradient in altitudinal range: and extension of Rapoport's latitudinal rule to altitude. Am Nat 140:893-911. https://doi.org/10.1086/285447 
Stout J, Vandermeer J (1975) Comparison of species richness for stream-inhabiting insects in tropical and mid-latitude streams. Am Nat 109:263-280. https://doi.org/10.1086/282996

Sutey P, Anderson J, Xu R, Rusak JA, Pereira C, Masters C, Evans D, Thomson C (2015) User Guide for the collection and submission of water samples. Ministry of Environment and Climate Change Chemistry Laboratory, Dorset, Ontario version 2016 2.0. https://desc.ca/water_chemistry. Accessed 30 Apr 2018

ter Braak CJF, Šmilauer P (2002). Canoco Reference Manual and CanoDraw for Windows User's Guide. Software for Canonical Community Ordination (version 4.5) Microcomputer Power. Ithaca, New York

Vannote RL, Minshall GW, Cummins KW, Sedel JR, Cushing CE (1980) The river continuum concept. Can J Fish Aqua Sci 37:130-137. https://doi.org/10.1139/f80-017

Vinson MR, Hawkins CP (1998) Biodiversity of stream insects: variation at local, basin, and regional scales. Annu Rev Entomol 43:271-293. https://doi.org/10.1146/annurev.ento.43

Yule CM, Leong MY, Liew KC, Ratnarajah L, Schmidt K, Wong HM, Pearson RG, Boyero L (2009) Shredders in Malaysia: abundance and richness are higher in cool upland tropical streams. J N Am Benthol Soc 28:404-415. https://doi.org/10.1899/ 07-161.1

\section{Publisher's Note}

Springer Nature remains neutral with regard to jurisdictional claims in published maps and institutional affiliations. 